Research Article

Lidia Buda-Ożóg*

\title{
Comparison of STM's reliability system on the example of selected element
}

https://doi.org/10.1515/eng-2021-0007

Received Jul 16, 2019; accepted Jun 17, 2020

\begin{abstract}
This paper presents optimization of the reliability system for different Strut and Tie models of beams loaded with a torsional and bending moment. In this paper, three STMs depending on the angle of diagonal strut were compared. The presented beam models have a serial system reliability. In the analyses, the full correlation of the top chord of truss - upper reinforcement, full correlation of bottom chord of truss - compression concrete, full correlation of members mapping individual stirrups and concrete in diagonals between stirrups. Estimation of the reliability of the adopted structures was carried out in a software package of Strurel. The variables of concrete, and steel strength as well as concentrated load magnitude were described by a mean value, a standard deviation and a type of distribution. Summing up the results of the analysis, it was noted, that methods for reliability estimation using information about the model's reliability structure are an excellent alternative to time consuming simulation methods. These methods allow not only to estimate the reliability of the structure, but also to determine the impact of individual members on the reliability of the entire element.
\end{abstract}

Keywords: strut and tie method, reliability system, serial structure, reinforced concrete beam, torsion

\section{Introduction}

The use of strut-and-tie model (STM) for the design of reinforced concrete structures has a very long history and is practically inseparable from the history of reinforced concrete structures. The concepts of the STM are originally referred to the truss analogy proposed by Ritter [1] and Mörsch [2] over a century ago. In the following years,

`Corresponding Author: Lidia Buda-Ożóg: Rzeszow University of Technology, ul. Poznanska, 35-084 Rzeszow, Poland; Email: lida@prz.edu.pl

๖ Open Access. @ 2021 L. Buda-Ożóg, published by De Gruyter. (cc) BY License strut-and-tie modelling techniques have been extensively investigated in comprehensive works by Thürlimann [3], Schlaich et al. [4], Kuchma [5] and many others. The STM idealizes a complex force flow in structures as a collection of compression members (struts), tension members (ties), and the intersection of such members (nodes).

The choice of the STM depending on the considered issue can be made by using truss analogies, the load path and knowledge of stress trajectories based on numerical models and topological optimization. Despite such a large number of studies, the standard recommendations and the literature do not provide rules to determine unambiguously the shape and direction of elements in the ST method, and the choice of the STM is usually made without reliability assessment of the obtained model.

The adopted ST models are characterized by a specified reliability structure. Analysing the connections of members in this structure and reliability of individual members of the structure the reliability of the entire system can be determined.

Information on the impact of individual components on the reliability of the whole system can be used to optimize the analysed ST models.

In this paper, based on information on the reliability structure of the adopted ST models, the methods of estimating and optimizing the reliability of the whole element are presented. The subject matter of the analysis are cantilever reinforced concrete beams loaded with a torsional and bending moment, having reinforcement arrangements obtained on the basis of different STM but preserving the same overall geometry and loading.

\section{Reliability structures of STM's}

From the point of view of reliability, the assumption that a technical object is a simple object is in practice often unjustified. An ordinary object consists of many interrelated members, each of which performs other tasks. Therefore, we are interested not only in the reliability characteristics of such an object as a whole, but also in the impact of the reliability of individual components or groups of compo- 
nents on the reliability of the whole object. Such systems usually do not show similarity to the modelled structure and are called heuristic models. The method of interrelations of members of a given system, defining the dependence of a system's failure on the failure of its members, is called the reliability structure of this system. The reliability structure of complex technical objects and the reliability of such objects can be analysed by various methods. In the case of building structures, the structure of system reliability should be limited to the consideration of two states, i.e. system members may be safe or fail, omitting intermediate states. There are several methods to assess the reliability of certain non-renewable systems that can be implemented in the analysis of the reliability of limit states of load bearing capacity of building elements and structures. Among them, non-renewable systems with serial-parallel structures are the most popular [6].

The system has a serial structure in the sense of reliability, the failure of one member leads to the failure of the entire system. The graphic illustrations of this structure for the $n$ - members of the system are shown in the Figure 1.

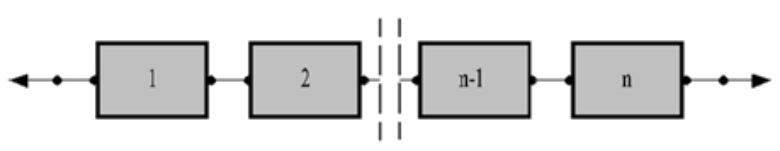

Figure 1: The n-members serial structures

If the failures of individual system members are independent events, then the probability that all members will be undamaged is equal to the product of the coefficients (probabilities) of the suitability of all members:

$$
Q=\prod_{i=1}^{n} Q_{i}=Q_{1} \cdot Q_{2} \cdot \ldots Q_{n}
$$

where:

$Q_{i}$ - the probability that the $\mathrm{i}$-th member of the system is not damaged

The probability of the failure of a system with a serial reliability structure is determined by the formula:

$$
P_{f}=1-\prod_{i=1}^{n}\left(1-P_{f i}\right)
$$

where:

$P_{f i}=1-Q_{i}$ - the probability of failure the $i$-th member.

Serial systems model the behaviour of statically determinate structures effectively. In the case of hyperstatic structures, the serial model can be used to estimate the minimum load bearing capacity of the system.
The system has a parallel structure in the sense of reliability if the system is failure when all system components are failure. The graphic illustrations of the parallel structure for n-elements are shown in the Figure 2.

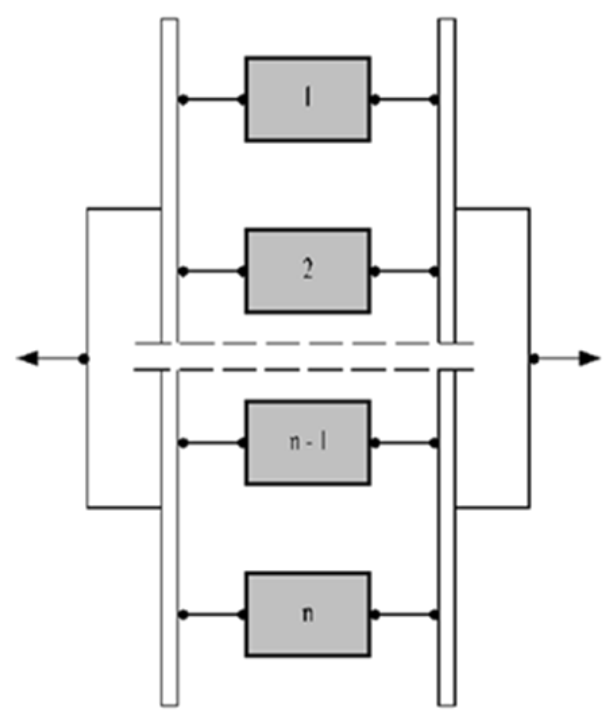

Figure 2: The $n$ - members parallel structures

For independently members, the reliability of the system is expressed by the following formula:

$$
Q=1-\prod_{j=1}^{m}\left(1-Q_{j}\right)
$$

where:

$Q_{j}$ - the probability that the $\mathrm{j}$-th member of the system is not damaged

The probability of a failure of a system with a parallel reliability structure is determined by the formula:

$$
P_{f}=\prod_{j=1}^{n} P_{f j}
$$

where:

$P_{f j}=1-Q_{j}$ - the probability of failure the $\mathrm{j}$-th member.

A parallel structure occurs when several members perform one and the same function. Only one member is enough to meet it, therefore the remaining members are spare members.

Many structures can be considered as a combination of series and parallel systems. Such systems are referred to as hybrid or combined systems. In the presented methods of analysing the reliability structure of complex technical objects and assessing their reliability, it was assumed that the failures of individual system components are in- 
dependent events. In practice, systems with different reliability structures consist of correlated members or groups of members. In case of two random variables $X$ and $Y$, the correlation coefficient is defined as:

$$
\rho_{x y}=\frac{\operatorname{Cov}(X, Y)}{\sigma_{x} \cdot \sigma_{y}}
$$

where:

$\operatorname{Cov}(X, Y)$ - covariance of random variables $X, Y$, $\sigma_{x}, \sigma_{y}$ - standard deviation of $X, Y$ random variables.

In real structures, the constant value of the correlation coefficient is a very rare phenomenon, usually individual elements of the system are differently correlated and described by the correlation matrix:

$$
\rho=\left[\begin{array}{cccc}
1 & \rho_{12} & \cdots & \rho_{1 n} \\
\rho_{21} & 1 & \cdots & \rho_{2 n} \\
\vdots & \vdots & \ddots & \vdots \\
\rho_{n 1} & \rho_{n 2} & \cdots & 1
\end{array}\right]
$$

The exact determination of the probability of destruction $-P_{f}$, a complex system with correlated elements is in practice very difficult, and sometimes even impossible. Therefore, complex systems usually estimate the range of extreme values of the correlation coefficient:

$$
\rho_{i j}=\left\{\begin{array}{l}
0-\text { when the elements are not correlated } \\
1-\text { when the elements are full correlated }
\end{array}\right.
$$

\section{Subject of analysis}

In this paper, three Strut and Tie Models (STMs) depending on the angle of diagonal strut were compared $[7,8]$. The angle of concrete compression diagonal struts were chosen so that the recommendations given in the national annex of the standard [9] for truss model were met. The first model (for B1 beam: ST1) was a spatial truss similar to the Leonhardt truss [10], in which the concrete compression diagonal struts, separated by cracks on each side of the vertical and horizontal element were inclined to the axis of the chords at the angle of $45^{\circ}$. The vertical elements of truss represent reinforcement in the shape of stirrups. The top and bottom chords of the truss represent tension reinforcement and compressed accordingly. In the second STM, the concrete compression diagonal strut were inclined to the axis of the chord at the angle of $37^{\circ}$ (for B2 beam: ST2), but in the third STM the diagonal struts were inclined at the angle of $26.6^{\circ}$. (for B3 beam: ST3). For all analysed beams (STM), the designed reinforcement was performed for the design load of $60 \mathrm{kN}$. The analysed model of cantilever beams are shown in Figure 3.
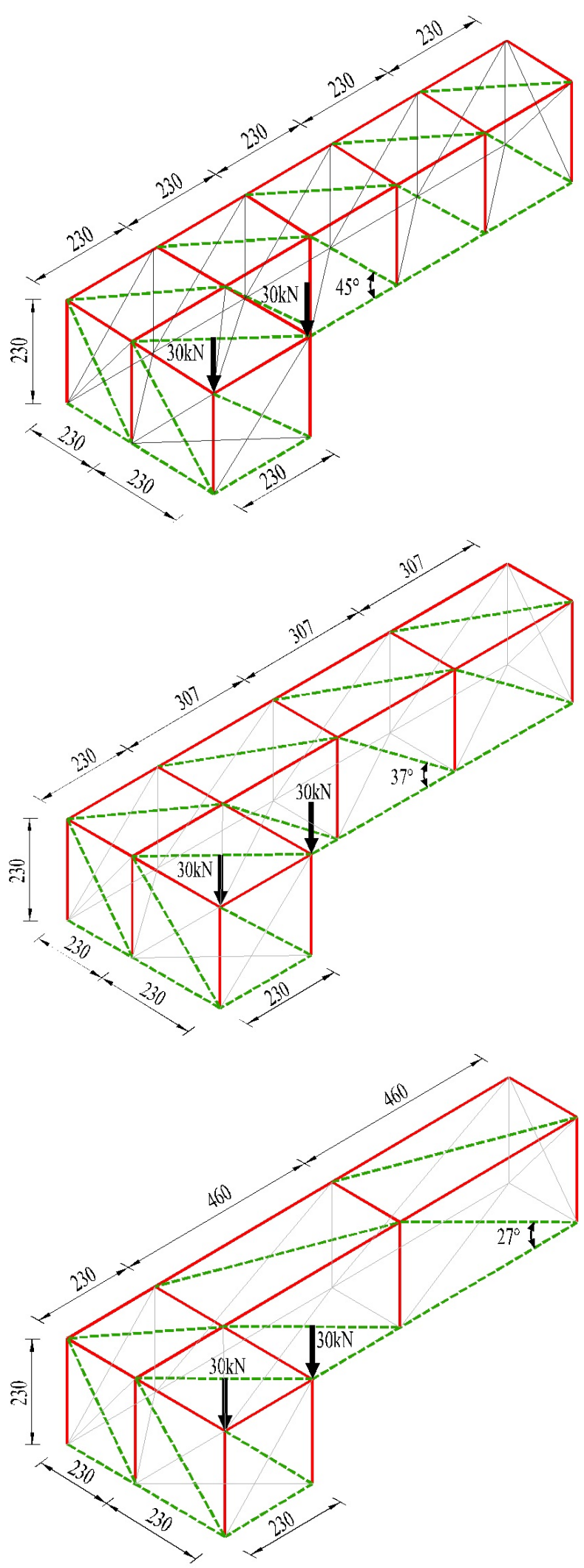

Figure 3: The analysed model of cantilever beams, a) beam B1, b) beam $B 2, c)$ beam $B 3$ 
On the basis of the obtained forces in the STM's, longitudinal reinforcement and stirrups were designed, the allowable compressive stresses in concrete struts of the STM and the anchorages of reinforcement were checked. The cross-section of analysed cantilever beams with reinforcement obtained on the basis of the adopted STM are shown in Figure 4.

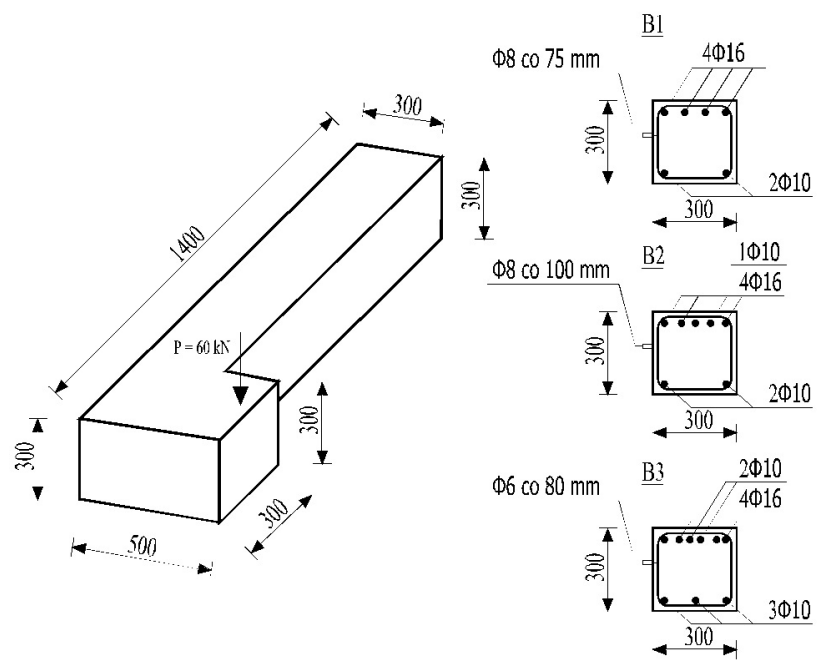

Figure 4: Geometry and reinforcement of the analysed beams

\section{System reliability of analysed STM's}

The presented beam models have a serial system reliability. Due to the method of making these types of members (the same concrete, the same reinforcement) in the analyses, the full correlation of the top chord of truss - upper reinforcement, full correlation of bottom chord of truss - compression concrete, full correlation of members mapping individual stirrups and concrete in diagonals between stirrups. The particular members of the $\mathrm{B} 3$ beam system reliability are shown in Figure 5. Analogous correlations of members were adopted for models B1 and B2 beams.

Estimation of the reliability of the adopted structures was carried out in a package of Strurel programs (Comrel, Costrel and Sysrel) enabling the user to define the functions of the limit state in symbolic processor notation. In case of normal and logarithmically normal variables, the structure of the model dependence can be given directly by means of correlation coefficients obtained from the covariance matrix, while in the complex model correlation

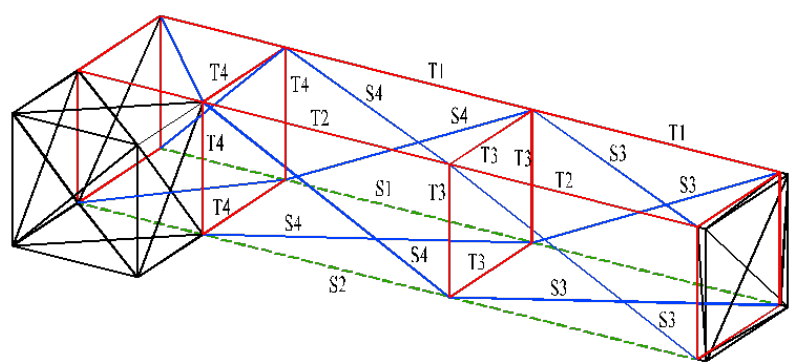

Figure 5: The particular members of the $B 3$ beam system reliability

coefficients in the input matrix should be given [11]. The Sysrel program for defined limit state functions of individual members and the type of system reliability (serial, parallel, complex) makes it possible to analyse the reliability of the whole structure. The limit state functions depending on the type of members in the STM are defined as follows:

$$
\begin{aligned}
& Z_{i}=A_{s i} \cdot f_{y}-F_{i} \\
& Z_{i}=\sigma_{\max (i)}-\frac{F_{i}}{t_{e f} \cdot a_{i}}
\end{aligned}
$$

where:

$Z_{i}$ - the limit state function of the i-th member,

$A_{s i}$ - the area of the reinforcement of the $\mathrm{i}$-th member,

$F_{i}$ - the force in the $\mathrm{i}$-th member of the STM is obtained for mean external loads,

$f_{y}$ - mean strength of reinforcing steel,

$\sigma_{\max (i)}$ - allowable compressive stresses in concrete struts of the STM

$t_{e f}$ - effective wall thickness of the hollow section in the torsion elements,

$a_{i}$ - width of the $\mathrm{i}$-th compressed strut

The statistic parameters were described using the recommendations specified in JCSS [12] and [13]. The input values should be properly described, e.g. with a mean value, a standard deviation or a type of distribution. The distribution and standard deviation for the input variables of concrete, steel and concentrated load are shown in Table 1 . The reliability of beams were assessed using probabilistic method FORM (First Order Reliability Metod) and SORM (Second Order Reliability Method). These are one of the most effective approximate methods for calculating reliability.

In the analyses, a correlation between the values of forces in individual ST members at the level of 0.9 was assumed. The reliability index estimated by the SORM method for individual members of the systems has been presented in Table 2. The values of the reliability index and the probability of failure of the whole system estimated by two methods, ie FORM and SORM, are compared in Table 3. 
Table 1: The mean value, standard deviation and distribution for the input variables

\begin{tabular}{cccc}
\hline Input & Mean value & $\begin{array}{c}\text { Standard } \\
\text { deviation }\end{array}$ & Distribution \\
\hline$f_{c}\left[\frac{N}{m m^{2}}\right]$ & 43 & 4.86 & Lognormal \\
$f_{y}\left[\frac{N}{m m^{2}}\right]$ & 545 & 27.25 & Lognormal \\
$P[k N]$ & 45 & 6.75 & Normal \\
\hline
\end{tabular}

Table 2: Reliability index of individual members in the reliability structures of the analysed beams

\begin{tabular}{cccccc}
\hline \multicolumn{2}{r}{ STM1 - B1 } & \multicolumn{2}{r}{ STM2 - B2 } & \multicolumn{2}{c}{ STM3 - B3 } \\
\hline Element & $\beta_{\text {SORM }}$ & Element & $\beta_{\text {SORM }}$ & Element & $\beta_{\text {SORM }}$ \\
$\mathrm{T}_{1}, \mathrm{~T}_{2}$ & 4.82 & $\mathrm{~T}_{1}, \mathrm{~T}_{2}$ & 5.24 & $\mathrm{~T}_{1}, \mathrm{~T}_{2}$ & 5.18 \\
$\mathrm{~T}_{3}, \mathrm{~T}_{4}$, & 6.61 & $\mathrm{~T}_{3}, \mathrm{~T}_{4}$, & 6.61 & $\mathrm{~T}_{3}, \mathrm{~T}_{4}$ & 6.61 \\
$\mathrm{~T}_{5}, \mathrm{~T}_{6}$ & & $\mathrm{~T}_{5}$ & & & \\
$\mathrm{~S}_{1}$ & 5.75 & $\mathrm{~S}_{1}$ & 6.86 & $\mathrm{~S}_{1}$ & 6.15 \\
$\mathrm{~S}_{2}$ & 9.32 & $\mathrm{~S}_{2}$ & 12.74 & $\mathrm{~S}_{2}$ & 9.86 \\
$\mathrm{~S}_{3}, \mathrm{~S}_{4}$, & 6.78 & $\mathrm{~S}_{3}, \mathrm{~S}_{4}$, & 6.50 & $\mathrm{~S}_{3}, \mathrm{~S}_{4}$ & 5.13 \\
$\mathrm{~S}_{5}, \mathrm{~S}_{6}$ & & $\mathrm{~S}_{5}$ & & & \\
\hline
\end{tabular}

Table 3: Reliability index and failure probability for whole system

\begin{tabular}{ccccc}
\hline Series & $\beta_{F O R M}$ & $P_{f_{F O R M}}$ & $\beta_{\text {SORM }}$ & $P_{f_{\text {SORM }}}$ \\
\hline B1 & 4.78 & $8.676 \cdot 10^{-7}$ & 4.82 & $7.185 \cdot 10^{-7}$ \\
B2 & 5.23 & $8.276 \cdot 10^{-8}$ & 5.24 & $7.888 \cdot 10^{-8}$ \\
B3 & 5.01 & $2.699 \cdot 10^{-7}$ & 5.02 & $2.541 \cdot 10^{-7}$ \\
\hline
\end{tabular}

Knowledge of the reliability structure allows determining the impact of the change of positional parameters and the distribution of random variables on the change of the index of system reliability. It is easy to assess the sensitivity of the system to changes in the quality of materials or permanent or variable load. An example of such an analysis may be the effect of changing the average compressive strength of concrete to the estimated value of the reliability index of the STM, as shown in Figure 6.

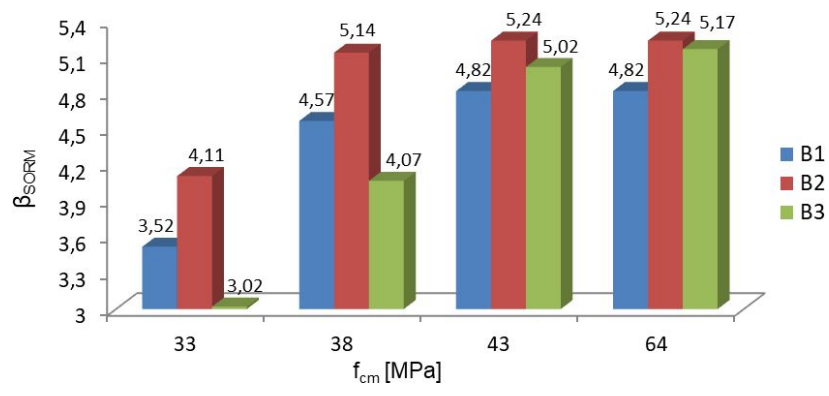

Figure 6: Impact of concrete strength on the reliability index of analysed STMs
Based on the conducted analyses, it can be concluded that the reliability structure of the ST3 model is more sensitive to a change of concrete class than the ST1 or ST2 model. In the case of concrete with a mean compressive strength of $33 \mathrm{MP}$ (concrete class $\mathrm{C} 25 / 30$ ), the safety condition of the RC2 construction reliability class and 50 years of use are not met. However, in the case of ST1 and ST2 models, the sensitivity of the reliability structure to the change of the concrete class above C30/37 is insignificant.

Knowledge of the reliability characteristics of the system members and their impact on the reliability of the whole structure allows increasing the safety of the structure, by increasing the reliability of the weakest members in the structure. Analysing the value of the reliability index of individual members, presented in Table 2, it can be noticed that $\mathrm{T} 1$ and $\mathrm{T} 2$ ties are characterized by the highest probability of failure. Increasing the adopted reinforcement area from $402 \mathrm{~mm}^{2}$ (2 $\phi 16 \mathrm{~mm}$ ) to $450 \mathrm{~mm}^{2}$ (2 $\phi$ $16 \mathrm{~mm}+1 \phi 8 \mathrm{~mm})$ in the above ties results in a change in the reliability index of the members from $\beta_{S O R M}=4.82$ to $\beta_{\text {SORM }}=5.93$. This results in a significant change in the probability of the whole system failure from $P_{f S O R M}$ $=8.676 \cdot 10^{-7}$ to $P_{f S O R M}=5.986 \cdot 10^{-9}$. The reliability index determined for the optimized reliability structure corresponding to the probability of failure is $\beta_{S O R M}=5.70$. Analogical optimization of the reliability structure can be carried out for the STM2, here the weakest members of the system are the ties: T1 and T2. By changing the surface of reinforcement by adding one bar $\phi 8 \mathrm{~mm}$, the reliability index of members increases from $\beta_{S O R M}=5.24$ to $\beta_{S O R M}=6.51$, and as a result, the probability of the whole system failure is reduced from $P_{f S O R M}=7.888 \cdot 10^{-8}$ on $P_{f S O R M}=9.392$. $10^{-11}$. The reliability index for such an optimized structure is $\beta_{\text {SORM }}=6.37$.

In the case of the STM3 model, increasing the reliability of the structure is not so easy as in the previous models. The Table 2 shows that in the STM3 model the weakest members are ties $\mathrm{T} 1$ and $\mathrm{T} 2$ and struts S3, S4. This means that increasing the reliability of the system requires increasing the class of concrete and the area of the reinforcement for ties $\mathrm{T} 1$ and $\mathrm{T} 2$.

\section{Conclusion}

The paper presents the probabilistic assessment of system reliability for different STM of beams loaded with a torsional moment, bending moment as well as a shear force. Summing up the results of the analysis, it was noted that methods for reliability estimation using information about 
the model's reliability structure are an excellent alternative to time consuming simulation methods. This methods allow not only estimating the reliability of the structure, but also determining the impact of individual members on the reliability of the entire element. Awareness of the reliability of individual members and their impact on the reliability of the whole system, allows its optimization so that the adopted model has the lowest probability of failure. Fulfilling the condition of the highest reliability of the analysed structure can be achieved by increasing the reliability of the weakest members in the system.

In this paper, it has been shown that the methods of estimating reliability using information about the model structure can be easily implemented to optimization of reliability of reinforced concrete structures designed on the basis of STMs.

\section{References}

[1] Ritter W. Die Bauweise Hennebique. Schweizerische Bauzeitung, vol. 33, Februry, pp. 41-43, 49-52 and 59-61, 1899.
[2] Morsch E. Der Eisenbetonbau seine Theorie und Anwendung. Stuttgart: Verlag K. Wittwer; 1929.

[3] Thurlimann, B. et al., Vorlesung Zum Fortbildungskurs Fur Bauingeniure, Eth Zuri: Institute Fur Bauststik Und Konstruktion, 1983.

[4] Schlaich J., Schäfer K., Jennewein M., Toward a consistent design of structural concrete. (PCI J 1987;32(3):74-150 1987.

[5] Kuchma D. i Tjhin, T., CAST (Computer Aided Strut-and-Tie) design tool. Structures Congress 2011.

[6] Nowak A. i Collins, K., Reliability of Structures. McGraw - Hill, 2000.

[7] Buda-Ożóg L. Assessment of stiffness beams subjected to combined shear and torsion designed using STM. Procedia Engineering. Tom. 2017;193:152-9.

[8] Buda-Ożóg, L., Niezawodność konstrukcji żelbetowych projektowanych metodą Strut and Tie, Oficyna wydawnicza Politechniki Rzeszowskiej, 2019 (in Polish).

[9] EN 1992-1-1, Eurocode 2: Design of concrete structures - Part 1-1: General rules and rules for buildings, 2004.

[10] Leonhardt F, Mönning E. Vorlesungen über Massivbau. Teil I. Berlin: Springer Verlag; 1973.

[11] Strurel, Technical Reference, User Manual. Munchen: RCP Consult GmbH; 2018.

[12] JCSS. Probabilistic model code. JCSS working material [online], http://www.jcss.ethz.ch/, 2012.

[13] Woliński S. Niezawodność konstrukcji budowlanych. Rozdziat 4.11, w: Praca zbiorowa, Budownictwo ogólne. T.3. Warszawa: Arkady; 2008. pp. 376-419. [(in Polish)]. 